\title{
Comparison of PMAC Machines for Starter-Generator Application in a Series Hybrid-Electric Bus
}

\author{
Sinisa Jurkovic and Elias G. Strangas \\ Department of Electrical and Computer Engineering, Michigan State University, East Lansing, MI 48824, USA \\ Correspondence should be addressed to Sinisa Jurkovic, jurkovi4@egr.msu.edu
}

Received 13 August 2010; Accepted 4 January 2011

Academic Editor: Tee Cheng

Copyright ( $) 2011$ S. Jurkovic and E. G. Strangas. This is an open access article distributed under the Creative Commons Attribution License, which permits unrestricted use, distribution, and reproduction in any medium, provided the original work is properly cited.

\begin{abstract}
This paper presents a comparative study of outer rotor PMAC machine candidates for starter-generator application in hybrid bus with series power train configuration. PMAC machines with interior and surface mount permanent magnets are considered and compared, although a complete analysis is only carried out for the SPM. Different design aspects such as concentrated versus distributed windings as well as interior and exterior rotor structures are evaluated. Different slot numbers per pole per phase configurations for concentrated winding PMAC machines are also examined. Comparison and evaluation of the machines is based on their performance which included evaluation of winding and iron losses, magnet losses, and maximum torque capability as well as the size and weight of the machines.
\end{abstract}

\section{Introduction}

With improvements in internal combustion engines performance and efficiency, with more recent improvements in electric motors, battery technology, and power electronics, and with increasing awareness in environment and fuel consumption, the idea of combining the two propulsion means appears to be a reasonable solution. Several variations of the hybrid combinations are available which can all be classified into four categories: series, parallel, series-parallel, or mild hybrid power train with each configuration having its advantages and disadvantages and best suited applications as described in [1]. In a series hybrid system, because the combustion engine is not directly connected to the wheels, it can be operated at the optimum point and can be turned off for temporary all-electric operation, reducing both fuel consumption and emissions [1]. In this paper, we focus on urban mass transportation vehicle, hybrid electric bus with series power train configuration. Heavy duty busses present excellent candidates for hybrid vehicles because of their size, which translates into a capability to carry the larger batteries and electrical machines required. Compared to passenger cars, busses operate at lower speeds, have limited acceleration, and usually run on lower road grades, all of which contribute to lower demand on electrical system. Because of the frequent stops, an added advantage is that a significant amount of energy can be recovered through regenerative breaking. In the last several years, there has been an increasing interest in integrated starter/alternators. Starting engines from a battery source has been common in the wide range of applications. With respect to hybrid vehicles, the integrated starter/alternator (ISA) configuration has been seriously explored in so-called mild hybrid topology, while less has been published on full hybrids and in particular on the series hybrid configuration. In mild hybrids, the integrated starter/alternator machine must be designed to have a very wide speed range operation. This role was reserved for induction or interior PMAC machines, because of their excellent field weakening capabilities. Cai in [2] presents a comparison of electrical machines for integrated starter-alternator applications but excludes the surface PM machine because of the wide speed range requirement. Chedot et al. in [3] provide the optimization procedure for the design of PMAC ISA, but only the interior PM (IPM) machine is considered due to its excellent field weakening range. Instead, in the case of the series hybrid configuration, the generator can be designed to have optimal operation at one speed and variable torque, that is, no 
field weakening. In starting mode, this machine should be capable of producing high torque at zero and low speeds. With these redefined requirements, a range of different machines can be considered for this purpose. In [4], ElRefaie proposed a fractional slot SPM with Slot/Pole/Phase $(\mathrm{SPP})=2 / 7$ for integrated starter-alternator application, but without comparison to SPM with SPP $=1 / 2$.

The balance of this paper is devoted to assessing the capabilities of three different machines as the candidates for integrated starter/alternator in series hybrid bus. The following machines are considered:

(i) interior permanent magnet machine,

(ii) surface permanent magnet machine with $\mathrm{SPP}=1 / 2$,

(iii) surface permanent magnet machine with $\mathrm{SPP}=2 / 7$.

The machines are compared with respect to iron losses, copper losses, and losses induced in the magnets and maximum torque as well as the size and weight. For the reminder of the paper, we will be comparing the PMAC machines with outer rotor configuration. This allows for the comparison of the IPM and SPM with the same air gap as the need for the retaining sleeve is eliminated in the SPM machines. It is also important to note that the IPM machine considered for the purpose of this study is so-called "Inset" type PM machine. A traditional IPM machine with single or double layer magnets is not considered as candidate for this application, since this type is only appropriate for the applications requiring wide speed range operation. The peak efficiency of those machines is usually at speeds higher than maximum power speed, that is, to the right of the corner speed on the torque-speed curve as shown in Figure 1. This implies that if such machine is designed to operate at or around the peak power, it will never operate at peak efficiency hence, SPM machines or "Inset" type machines are more suitable candidates for the given application.

The major contributions of this paper are to augment the work carried out by El-Refaie [4] by including the 1/2 SPP topology in the comparison of SPM machines with fractional slot windings; to lay out the procedure and available tools for analytical prediction of the performance of surface PM machines with fractional windings; finally, to carry out the comparison of the SPMAC machines with outer rotor for ISG application in a series HE Vehicles.

\section{System Configuration}

The objective is to design a starter-generator machine for series hybrid bus configuration. The series hybrid vehicle topology considered is shown in Figure 2.

In this topology, the engine is not directly linked to the transmission for mechanical driving power. All the energy produced by the engine is converted to electric power by the generator, which provides the power for the traction motor and charges the energy storage device. The electric motor system provides torque to the wheels of the vehicle. The engine is operated at the optimum point to minimize the fuel consumption and emissions. A typical efficiency map of a

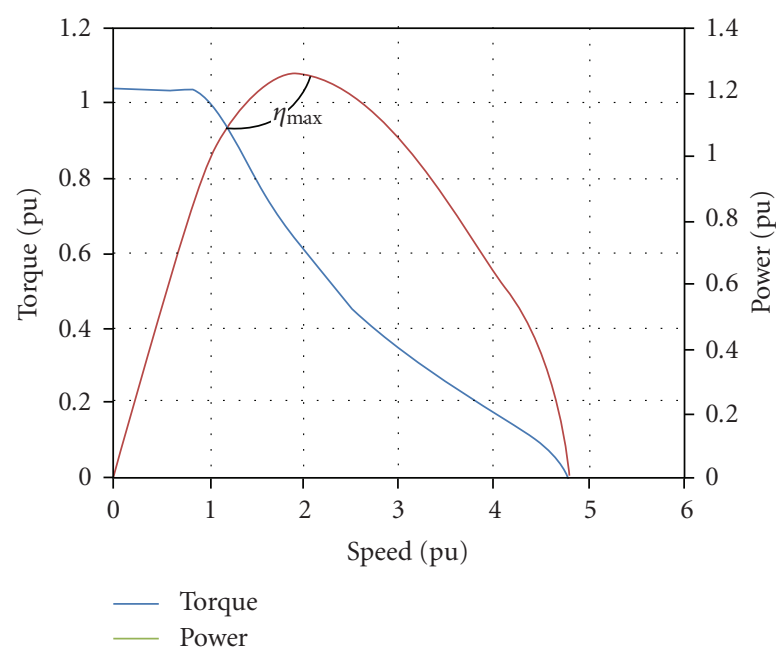

(a)

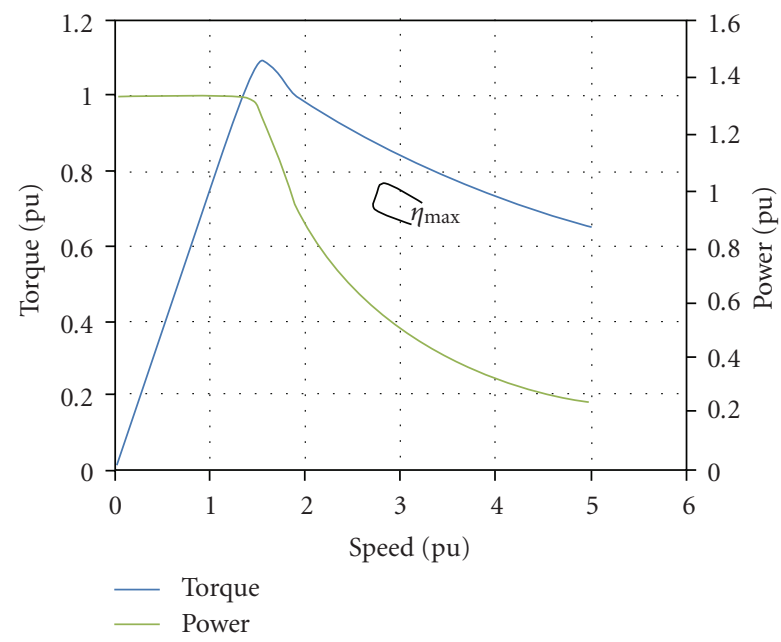

(b)

FIGURE 1: Torque and power versus speed for (a) SPM machine and (b) IPM machine.

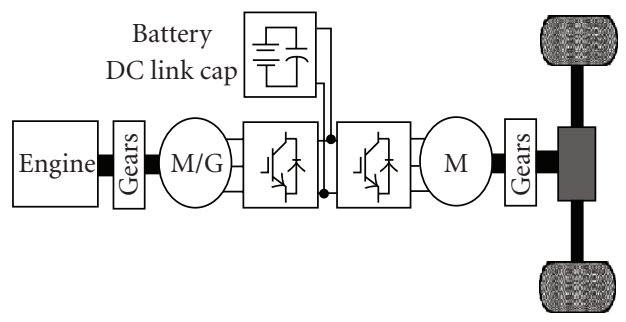

Figure 2: Series HEV powertrain configuration.

diesel-type engine shown in Figure 3 clearly shows the points of higher efficiency around peak torque.

From this figure, we can conclude that for maximum efficiency in this particular case, the engine should operate at a speed around 1800 RPM. This means that the generator will also operate at constant speed and variable torque, which further means that no field weakening operation will be required. In the starting mode, the machine must provide 


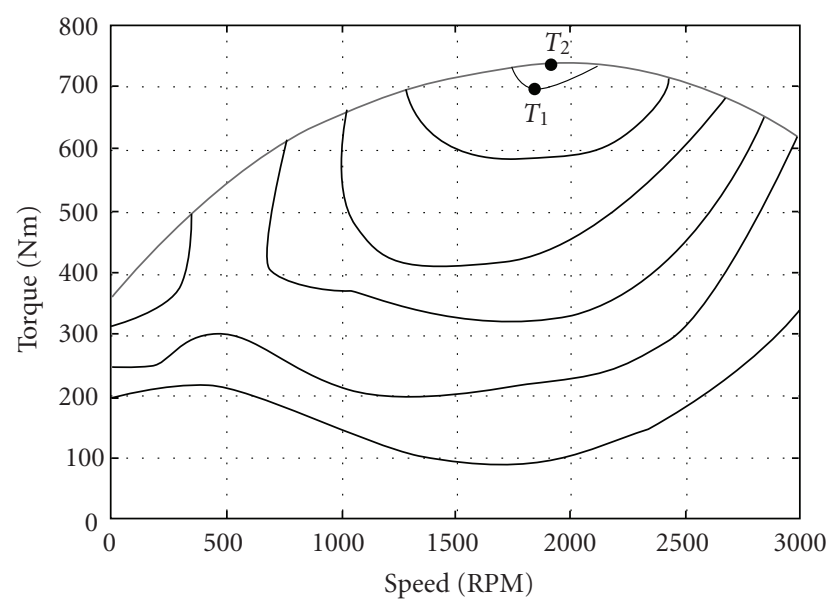

FIgURE 3: Typical fuel map of a diesel engine.

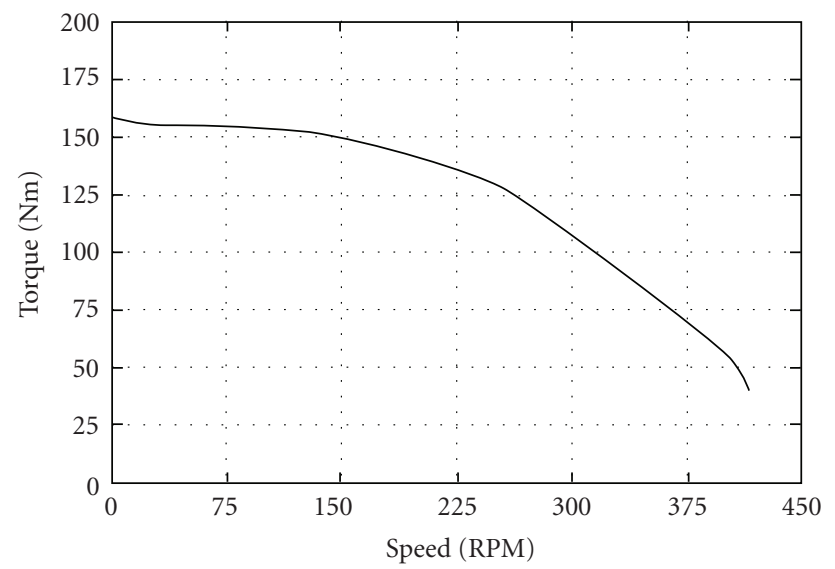

FIGURE 4: Cranking torque requirement of $6 \mathrm{~L}$ diesel engine.

enough torque to start the engine. The starting torque requirement of an engine is shown in Figure 4 [5].

For starting of a diesel engine, constant power is required for the speed range from zero to approximately 250 RPM. The PMAC generator, now operating as a motor, has to produce high torque at zero speed, and as the speed is increased, the required torque is decreased. The major requirements for starter-alternator can be summarized as

(1) relatively high electrical frequency of voltages and currents to reduce the size of filtering components,

(2) high power to mass ratio $\geq 1.65 \mathrm{~kW} / \mathrm{kg}$,

(3) high efficiency $\geq 90 \%$ at the rated operating point,

(4) high thermal endurance.

\section{Sizing the Generator}

Given the series configuration of the hybrid electric bus, the sizing of a generator must take into consideration the most efficient conditions of the IC engine in terms of fuel consumption and emissions, which in practice can be accomplished by keeping the operating speed constant and allowing small torque variations as shown in Figure 3. We define two operating modes of the HE bus; Mode IWinter Mode, that is, with air conditioning and Mode II-Summer Mode, that is, without air conditioning. Now instead of having continuous torque variation, we will simply assume that the engine will operate at two discrete operating points, $T_{2}$ and $T_{1}$, shown in Figure 3 , corresponding to two operating modes I and II, respectively. It is obvious that we must size the generator to satisfy the maximum power requirement which means operation with air conditioning or Mode I. From this point on, we can assume that generated power will be kept constant independently of the load demand. The most obvious choice of the generator output power in such case as in [6] would be given by

$$
P_{\mathrm{GEN}}=P_{\mathrm{DC}}
$$

where $P_{\mathrm{DC}}$ is the average required power from the DC bus including both power for propulsion motors and auxiliary electrical loads. In this case, the average net power required for traction (including the regenerative breaking) and electrical loads will be supplied by the generator while the transients will be covered by the battery. The energy used for battery charging will come from the generator and regenerative breaking. This approach assumes that the generator is always turned on, and it would require the engine size to match the generator size which is not practical since the engines are available in discrete sizes. A more realistic approach would assume somewhat greater engine and generator size and the vehicle operating in two different modes during a driving cycle: (1) generator is on and (2) electric only mode. In this case, if the generator power is chosen as shown above, it may cause the battery state of charge (SOC) to fall very low at times, reducing its lifetime dramatically. In order to avoid this problem, initial and final SOC during a drive cycle must be taken into account when designing the electric generator of the series HEV. At the very minimum, we must ensure that

$$
\mathrm{SOC}_{\mathrm{END}} \geq \mathrm{SOC}_{\mathrm{MIN}}
$$

or for the upper limit of the generator size

$$
\mathrm{SOC}_{\mathrm{END}}=\mathrm{SOC}_{\mathrm{START}} \text {. }
$$

Fulfilling this condition will ensure the bus availability for next trip without necessary stop for battery charging. We can now rewrite the generator power equation (1) as

$$
P_{\mathrm{GEN}}=P_{\mathrm{DC}}+P_{\mathrm{BAT}},
$$

where the $P_{\mathrm{BAT}}$ will ensure recharge of the battery. In the interval when the vehicle operates in fully electric mode, the battery will be the only source of energy $E_{\mathrm{BAT}}$. During the time when the generator is on, it should deliver energy supplied by the battery and fulfill the requirements of $P_{\mathrm{DC}}$. So, we can write the following:

$$
E_{\mathrm{GEN}}=E_{\mathrm{BAT}}+\int_{t}^{t_{1}}\left(P_{\mathrm{DC}}-P_{\mathrm{GEN}}\right) d t
$$


where $t-t_{1}$ is the time interval the generator is on. So, $P_{\mathrm{BAT}}$ can be calculated as

$$
P_{\mathrm{BAT}}=\frac{E_{\mathrm{BAT}}}{t-t_{1}} .
$$

Using the above equations and ADVISOR simulation results for HE bus on US federal driving cycle, we obtain the generator power requirement of $91 \mathrm{~kW}$. This of course accounts for the efficiency of all the components (PWM inverter, traction motor, and gears) between the generator and wheels $\eta_{\mathrm{TR}}=71 \%$ and recharge efficiency of the battery $\eta_{\mathrm{BAT}}=91 \%$.

\section{Rotor Topology Selection}

The first step was to choose between the surface permanent magnet and the interior permanent magnet machine. Towards that end, we examined the two different rotor topologies, shown in Figure 6, to determine the one best suited to meet our requirements. It is often stated that an IPM machine is capable of producing higher torque than a similar SPM machine. This is greatly due to the larger air gap (lower flux density) in the SPM machines, which is necessary to accommodate the magnets retaining sleeve. In order to eliminate this disadvantage in the SPM machines, for the purpose of this study, we will consider outer rotor surface permanent magnet machine. An initial study was carried out to show that IPM machines with inner and outer rotors will have the same electromagnetic behavior. The machines compared are shown in Figure 5, along with power comparison graph. We can see that almost identical power-speed performance is obtained, with the exception of high speed, where the conventional machine has somewhat higher power. By increasing the rotor back iron, a power boost at high speed would be possible in the outer rotor machine as well; however, since our application will not require the machine to operate in that region, no further optimization effort is made. The point of this comparison is merely to show that similar power-speed characteristics can be obtained from both conventional and outer rotor machines. We will now compare the optimized conventional IPM machine versus outer rotor SPM machine. In [7], a similar comparison was carried out on five types of rotor magnet topologies to compare the performance of IPM versus SPM. The study was performed by determining the characteristics of motors with each rotor topology and a stator that was the same for all of the variants. The rotor outer diameter, length, type of magnet, and the magnet thickness were kept the same for all cases. It was determined that buried magnet topologies have an output power less than the surface magnet topologies as well as higher back EMF THD. In particular, the SPM had 5\% advantage in maximum power output over the IPM for the two machines of the same ratings as well as $2 \%$ THD advantage. In [8], Cross and Viarouge concluded that compared to the embedded magnets, one important advantage of the surface-mounted magnets is the smaller amount of magnet material needed in the design (in integer-slot machines) for the same power. Reportedly, $18 \%$ less magnetic material is used in SPM versus

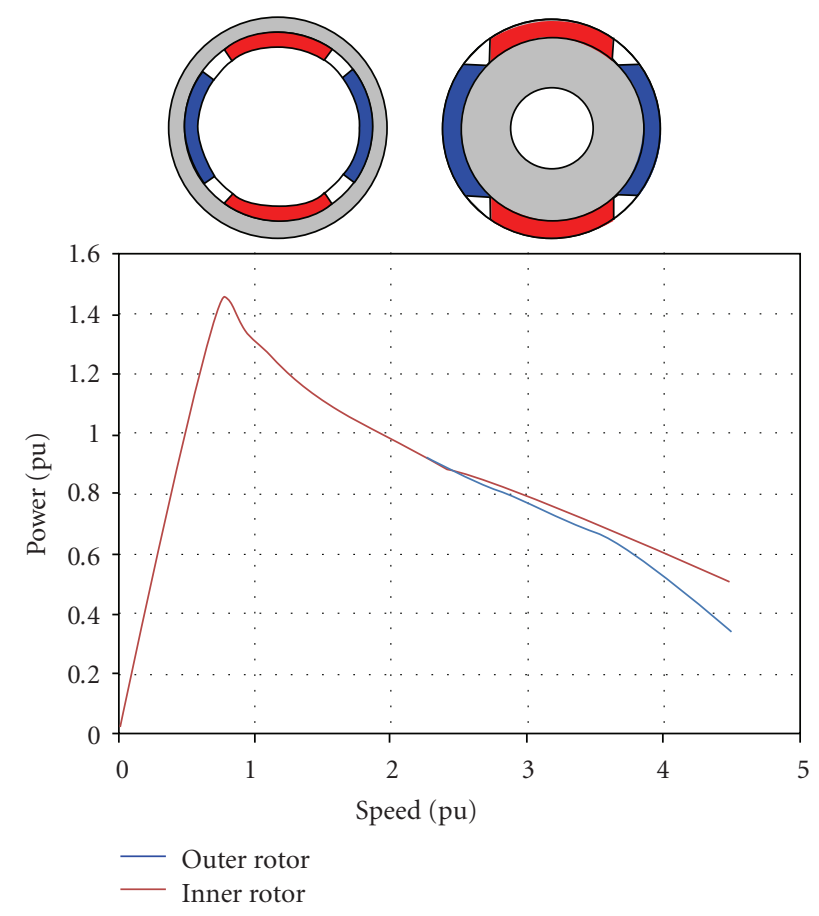

FIGURE 5: Outer and inner rotors of an inset magnet PM machines candidates are shown on the top, and corresponding power-speed curves are shown below.

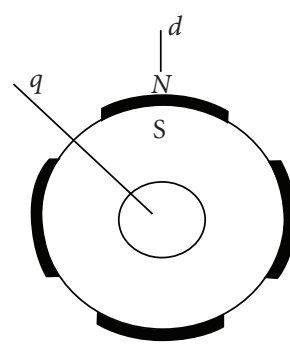

(a)

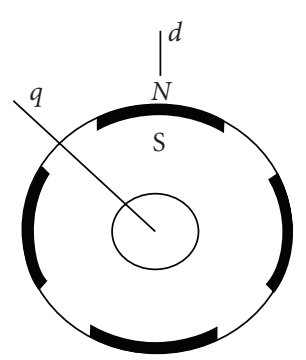

(b)
FIGURE 6: SPM and IPM rotor configuration considered in the comparison.

IPM for the machines of the same power rating. This is due to the fact that in the embedded magnets case there is always a considerable amount of leakage flux in the end regions of the permanent magnets. For the purpose of this paper in all further comparison, smaller scaled version of the motor-generator design will be considered. Both SPM and IPM machines were designed for rated condition of $6 \mathrm{~kW} 6000 \mathrm{RPM}$. The active size of the machines, number of poles, and flux per pole are kept constant for both machines. It was established through Flux 2D FEM simulation that the magnet width variation changed maximum torque production and torque ripple of the machine. Relative width of the magnets for IPM was optimized to 0.8 of the pole pitch for maximum torque.

The details of the SPM machine are presented in Section 6 and Table 7. The IPM machine considered here is 


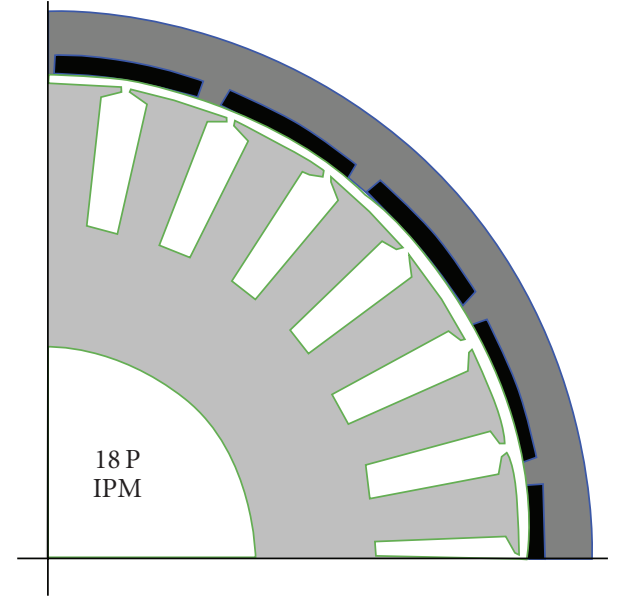

Figure 7: 18-pole, 6kW IPM machine.

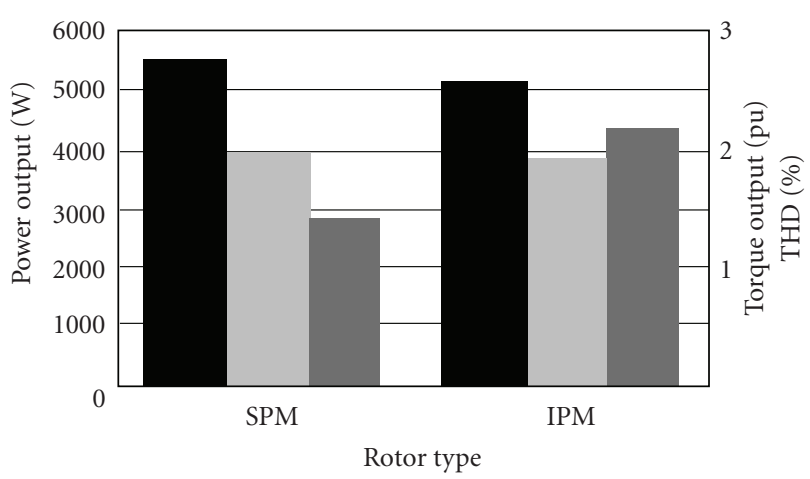

Power

Torque

- THD

Figure 8: Maximum torque, output power, and THD of $6 \mathrm{~kW}$ SPM and IPM machines.

the one with concentrated windings, 18 poles, and the rotor topology shown in Figure 7. From the graph in Figure 8, it can be seen that the efficiency of IPM is $90 \%$ compared to $92 \%$ for the SPM machine. It is clear that the SPM will provide higher output power and torque, as well as lower THD, which will in turn reduce iron and magnet losses as it will be shown in a later section. The maximum torque output for the SPM is $2.01 \mathrm{pu}$, while the maximum torque of IPM is less than 1.9 pu. From the results presented here, it is clear that the SPM has better performance, and it is a more suitable candidate for our application.

Lower THD will in turn reduce iron and magnet losses as it will be shown in later section.

\section{Concentrated or Distributed Windings}

A permanent magnet machine can have a variety of winding structures as shown in Figure 9. Early and large PMAC machines had sinusoidally distributed windings, while in the last several years concentrated windings have been increasingly used due to short-end turns and simple structure
TABLE 1: Specification of the IPM machine.

\begin{tabular}{lc}
\hline Slot opening width & $2.5(\mathrm{~mm})$ \\
Slot top width & $5.4(\mathrm{~mm})$ \\
Slot height & $24.9(\mathrm{~mm})$ \\
Tooth width & $7.4(\mathrm{~mm})$ \\
Slot bottom width & $7.6(\mathrm{~mm})$ \\
Slot opening height & $3.0(\mathrm{~mm})$ \\
Back iron depth & $5.4(\mathrm{~mm})$ \\
Phase resistance & $0.72(\Omega)$ \\
Magnet depth & $6.3(\mathrm{~mm})$ \\
\hline
\end{tabular}

TABLE 2: Comparison of concentrated versus distributed windings machine.

\begin{tabular}{lcc}
\hline & $\begin{array}{c}\text { Concentrated } \\
\text { windings }\end{array}$ & $\begin{array}{c}\text { Distributed } \\
\text { windings }\end{array}$ \\
\hline Copper losses $(\mathrm{pu})$ & 0.03 & 0.038 \\
Copper weight $(\mathrm{kg})$ & 1.6 & 2.2 \\
End-turns copper \% & 25 & 46 \\
Fill factor $(\%)$ & 72 & 61 \\
\hline
\end{tabular}

suitable for high volume automated manufacturing. They are not yet frequently used in larger electrical machines, where smooth torque production is very important.

There are several advantages to concentrating windings around the teeth. Table 2 shows the comparison of the copper losses for distributed and concentrated windings for the $6 \mathrm{~kW}$ SPM machine. It is clear that there is a reduction in the Joule losses in the end region due to shorter end turns, by $32 \%$ in this case. Additional advantages of the concentrated windings machine over the one with distributed windings are

(1) reduction in cost made possible by simplified manufacturing,

(2) reduction of the copper mass in the machine by $38 \%$, as shown in Table 2 for the same size machine,

(3) easier to fabricate compared to the distributed lap winding particularly when the stator can be segmented into separate stator poles,

(4) higher slot fill factor can be achieved, 72\% for concentrated windings machine with SPP $=0.5$ versus $61 \%$ for distributed windings machine.

Concentrated windings can be used in the design of modular PM brushless machines with higher numbers of phases to improve fault tolerance [9].

It should be noted here that a disadvantage of a concentrated wound machine is a lower leakage inductance, which in turn could make the machine more prone to demagnetization. However, this issue is not considered in this comparison since our application will limit the machine operating point to a very narrow speed range as described in Section 2. 


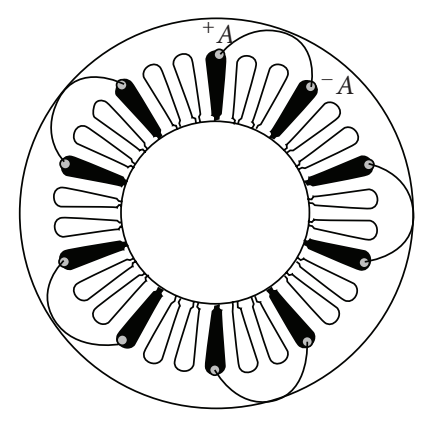

(a)

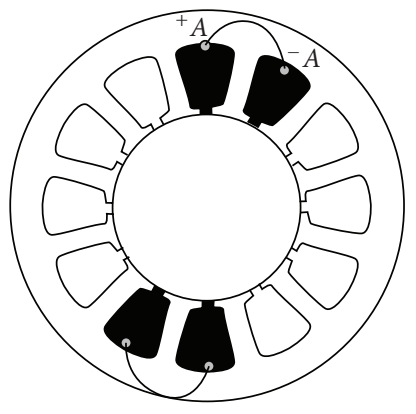

(b)

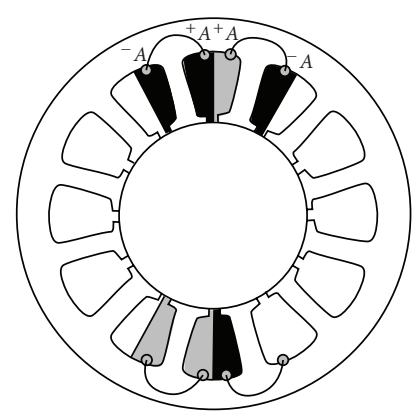

(c)

FIGURE 9: End windings of one phase of a 8-pole-machine: (a) a traditional one-layer winding (b) a one-layer fractional (c) a two-layer fractional slot winding

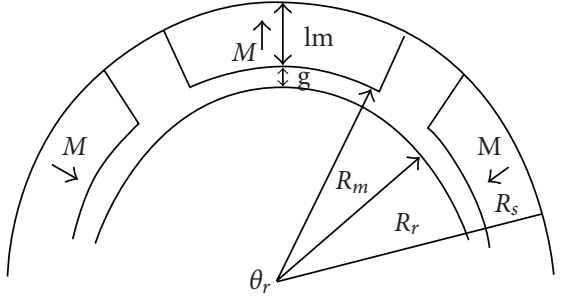

FIGURE 10: Outer rotor SPM machine.

\section{Loss Calculation}

In this section, the various types of losses in the machine will be calculated in order to calculate the machine efficiency and output (shaft) power. The main types of losses are the copper losses in the windings, core losses (in the stator teeth and stator back iron), losses in the retaining sleeve (if one is used), and losses in the magnets.

6.1. Copper Losses. From the phase current and the phase hot resistance, the machine copper losses can be calculated as follows:

$$
\begin{aligned}
P_{\mathrm{cu}} & =3\left(\mathrm{I}_{\mathrm{ph} \_\mathrm{RMS}}\right)^{2} R_{\mathrm{ph} \_ \text {hot }}, \\
R_{\mathrm{ph} \_ \text {hot }} & =R_{\mathrm{ph} \_ \text {hot }}\left(1+\alpha_{\mathrm{cu}}\left(T_{\text {hot }}-T_{o}\right)\right),
\end{aligned}
$$

where $\alpha_{\mathrm{cu}}$ is copper temperature coefficient, $T_{\text {hot }}$ is machine winding hot operating temperature, and $T_{o}$ is the room temperature.

The resistance calculation is straightforward, except for estimating an average length of the concentrated winding turns. The lengths of the winding end turns vary as the turns move further away from the tooth wall. A model derived in [4] is used, for calculating the resistance of a concentrated winding including the end region. The analytical calculation of the copper losses for two different machine configurations is shown in Table 3.

6.2. Iron Losses. The variation of the flux density in the stator teeth and yoke of PM motors is generally not sinusoidal. Therefore, the approach to core loss calculations based on

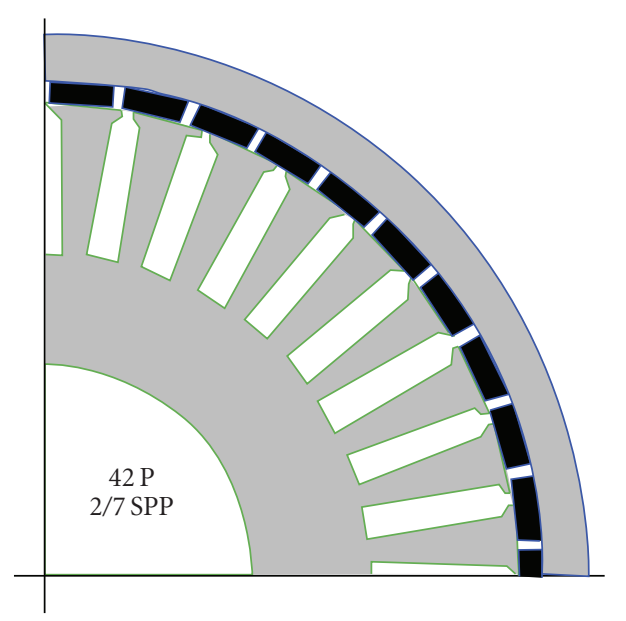

FIGURE 11: Concentrated winding SPM with 2/7 SPP.

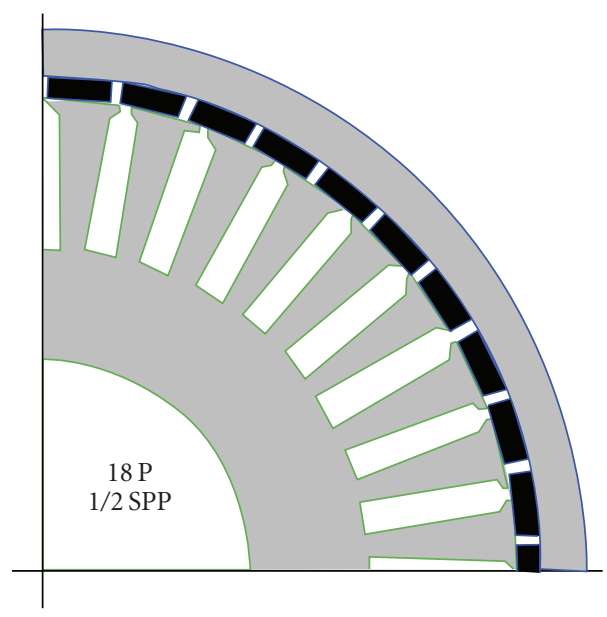

FIGURE 12: Concentrated winding SPM with 1/2 SPP.

the assumption that only the fundamental component of the flux density exists is not valid. For good estimation of core losses, the effects of harmonics have to be taken into account. Some authors also accounted for the commutation-induced core losses. In this analysis, the focus is only to calculate 
TABLE 3: Analytical results of copper losses calculation of the outer rotor SPM.

\begin{tabular}{lcc}
\hline & $\mathrm{SPP}=2 / 7$ & $\mathrm{SPP}=1 / 2$ \\
\hline Copper losses $(\mathrm{W})$ & 107 & 131 \\
\hline
\end{tabular}

TABLE 4: Analytical results of iron losses calculation.

\begin{tabular}{lcc}
\hline & $\mathrm{SPP}=2 / 7$ & $\mathrm{SPP}=1 / 2$ \\
\hline Iron losses $(\mathrm{W})$ & 168 & 187 \\
\hline
\end{tabular}

TABLE 5: Analytical results of magnet losses calculation.

\begin{tabular}{lcc}
\hline & $\mathrm{SPP}=2 / 7$ & $\mathrm{SPP}=1 / 2$ \\
\hline Magnet losses $(\mathrm{W})$ & 131 & 95 \\
\hline
\end{tabular}

the eddy current and hysteresis losses. The commutationinduced losses are not taken into consideration since they depend on the switching scheme of the converter. The model presented in [4] is used for the present analysis. This model is an improved approximate version of that presented by Atallah et al. in [10] for calculating the core losses. It is directly related to the machine dimensions and material properties, which makes it suitable for preliminary machine design and efficiency estimation. Total iron losses can be calculated as follows:

$$
P_{\text {iron }}=\left(P_{\text {et }}+P_{\text {ht }}\right) V_{t}+\left(P_{\text {ey }}+P_{\text {hy }}\right) V_{y},
$$

where $P_{\text {et }}$ is the stator tooth eddy current power loss per unit volume, $P_{\text {ey }}$ is the stator yoke eddy current power loss, $P_{\mathrm{ht}}$ is the stator tooth hysteresis power loss per unit volume $\left[\mathrm{W} / \mathrm{m}^{3}\right]$, and $P_{\text {hy }}$ is the stator yoke hysteresis power loss per unit volume $\left[\mathrm{W} / \mathrm{m}^{3}\right] . V_{y}$ and $V_{t}$ are the total volumes of the yoke and teeth, respectively. Table 4 shows iron losses comparison for the SPM machines with SPP $=2 / 7$ and SPP $=1 / 2$.

6.3. Magnet Losses. Several authors have addressed the issue of eddy current losses in the magnets in case of surface and interior PM machines $[4,10]$. There are three main sources of the eddy currents induced in the magnets. These are the stator winding space harmonics, the stator current time harmonics, and the space harmonics due to slotting effects. In surface PM machines, it can be assumed that the losses due to slotting effects can be neglected due to the large effective air gap. In general, magnet losses in ferrites and bonded magnets are much lower compared to sintered magnets since they have high resistivity.

The analytical model presented by Atallah et al. in [10] was applied for calculating the losses in the magnets of SPM. This model presented in $[4,10,11]$ was developed to include losses caused by the time harmonics of the stator currents and space harmonics of the stator windings. In the case of surface PM with concentrated windings, the stator windings space subharmonics are the dominant factor in inducing eddy current losses, while the losses caused by stator current time harmonics are comparably lower; hence, the model presented here is a simplified one to include only the dominant losses. The full model is presented by Ishak et al. in [11]. The basic assumptions in this model are

(i) the current in the stator windings is approximated by an equivalent current sheet;

(ii) the rotor iron core is laminated and has infinite permeability, thus no core losses are present;

(iii) the model presented is $2 \mathrm{D}$ in polar cordinates, thus eddy currents which induce losses in the magnets are in the axial direction only;

(iv) the magnets are assumed homogeneous and isotropic;

(v) the eddy currents are only resistance limited.

The stator winding can be represented with the following equivalent current sheet:

$$
J_{S}\left(\theta_{S}, t\right)=\left\{\begin{array}{r}
+\frac{m}{2} \sum J_{n} \cos \left(n p_{s} \theta_{S}-p_{r} \omega_{r} t\right), \\
n=m k+c, \\
-\frac{m}{2} \sum J_{n} \cos \left(n p_{s} \theta_{S}+p_{r} \omega_{r} t\right), \\
n=m k-c, \\
n \neq m k \pm c .
\end{array}\right.
$$

In the rotor frame of reference, the current sheet can be rewritten as follows:

$$
J_{S}\left(\theta_{S}, t\right)=\left\{\begin{array}{r}
+\frac{m}{2} \sum J_{n} \cos \left(n p_{s} \theta_{r}-\left(n p_{s}-p_{r}\right) \omega_{r} t\right), \\
n=m k+c, \\
-\frac{m}{2} \sum J_{n} \cos \left(n p_{s} \theta_{S}+\left(n p_{s}+p_{r}\right) \omega_{r} t\right), \\
n=m k+c, \\
n \neq m k \pm c,
\end{array}\right.
$$

where $c= \pm 1$, and $J_{n}$ is defined as:

$$
J_{n}=\left(2 N_{\text {phase }}\left(\frac{\mathrm{I}_{m}}{\pi R_{s}}\right)\right) K_{w n}
$$

with the following definitions: $J s$ is equivalent current sheet, $J m$ is induced eddy current density in the PM, $n$ is spatial harmonic order, $p_{s}$ is fundamental stator winding pole pairs, $p_{r}$ fundamental rotor winding pole pairs, $\omega_{r}$ is rotor angular velocity, $N$ is number of phases, $N_{\text {phase }}$ is number of series turns/phase, $I_{m}$ is peak phase current, $\theta_{S}$ is angle along the stator, and $\theta_{r}$ is angle along the rotor. The induced eddy current loss in one magnet segment can be derived as follows:

$$
P_{m}=\frac{\omega_{r}}{2 \pi} \int_{0}^{2 \pi / \omega_{r}} \int_{R_{n}}^{R_{r}} \int_{-\alpha_{m} / 2}^{\alpha_{m} / 2} \rho_{m} J_{m}^{2} r d_{r} d \theta_{r} d t
$$

or

$$
P_{m}=\sum_{n=1}^{\infty}(P c n+P a n)
$$




$$
\begin{aligned}
P_{c n} & =\frac{m^{2} \mu_{o}^{2} \alpha_{m} J_{n}^{2}}{8 \rho_{m} n^{2} p_{s}^{2}}\left(n p_{s} \pm p_{r}\right) 2 \omega_{r}^{2} \\
& * \frac{\left[\left(\frac{R_{s}}{R_{m}}\right)^{2 n p_{s}} R_{s}^{2} R_{m}^{2} F_{n}+\left(\frac{R_{s}}{R_{r}}\right)^{2 n p_{s}}\left(\frac{R_{s}^{2} R_{s}^{2}}{\left(2 n p_{s}+2\right)}\right) *\left(1-\left(\frac{R_{m}}{R_{r}}\right)^{2 n p_{s}+2}\right)+\left(\frac{R_{s}}{R_{r}}\right)^{2 n p_{s}} R_{s}^{2}\left(R_{r}^{2}-R_{m}^{2}\right)\right]}{\left[1-\left(\frac{R_{s}}{R_{r}}\right)^{2 n p_{s}}\right]^{2}},
\end{aligned}
$$

where

$$
\begin{aligned}
& F_{n}=\left\{\begin{array}{l}
\frac{\left(R_{r} / R_{m}\right)^{-2 n p_{s}+2}-1}{\left(-2 n p_{s}+2\right)}, \quad n p_{s} \neq 1, \\
\ln \left(\frac{R_{r}}{R_{m}}\right), \quad n p_{s}=1,
\end{array}\right. \\
& P_{a n}= \frac{m^{2} \mu_{o}^{2} J_{n}^{2}}{\alpha_{m} \rho_{m} n^{4} p_{s}^{4}}\left(n p_{s} \pm p_{r}\right) 2 \omega_{r}^{2} \\
& *\left[\left(R_{s} / R_{m}\right)^{2 n p_{s}} R_{s}^{2} R_{m}^{2} G_{n}+\left(R_{s} / R_{r}\right)^{2 n p_{s}}\right. \\
& *\left[\begin{array}{l}
\left.\times\left(R_{s}^{2} R_{s}^{2} /\left(2 n p_{s}+2\right)\right) *\left(1-\left(R_{m} / R_{r}\right)^{2 n p_{s}+2}\right)\right]^{2} \\
{\left[\begin{array}{l}
\left(R_{r}^{2}-R_{m}^{2}\right)\left(1-\left(R_{s} / R_{r}\right)^{2 n p_{s}}\right)^{2}
\end{array}\right],}
\end{array}\right. \\
& G_{n}=\left\{\begin{array}{l}
\frac{\left(R_{r} / R_{m}\right)^{-n p_{s}+2}-1}{\left(-n p_{s}+2\right)}, \quad n p_{s} \neq 2, \\
\ln \left(\frac{R_{r}}{R_{m}}\right),
\end{array}\right] p_{s}=2 .
\end{aligned}
$$

With the analytical portion of the analysis concluded, we now focus on finite element analysis (FEA).

\section{Finite Element Analysis}

In this section, we present the results of FE simulation for the two machine candidates. The finite element analysis program used in the computations is Cedrats Flux2D version 10.1. It computes for plane sections (problems in the plane or problems with rotational symmetry) the magnetic, electric, or thermal states of devices. These states allow computation of several quantities: field, potential, flux, energy, force, and so forth. The quantities obtained would be difficult to calculate by other methods (analytical computations, prototypes, tests and measurements). Two SPM machines are designed and compared. As a starting point, we used the SPM with SPP $=2 / 7$ designed and presented by El-Refaie in [4]. Our goal is to design a comparable SPM with $1 / 2$ slot/pole/phase. For the comparison, we will keep amount of the magnet material constant, rated speed $3000 \mathrm{rpm}$, and rated power $6 \mathrm{~kW}$, as well as the active diameter of the machine. Based on these constraints, an SPM machine was designed with 27 slots, 18 poles concentrated winding. Through a series of FEM simulations, the relative width of the magnets was optimized to 0.86 for maximum torque. The geometries of the two machines are shown in Figures 11 and 12 , respectively. The air gap of both machines is kept constant at $0.95 \mathrm{~mm}$.

The detailed specification of the SPP $=2 / 7$ and the SPP $=$ $1 / 2$ machines is provided in Tables 6 and 7, respectively.

In order to compare the candidates, we calculate the losses of the machines to obtain the operating point efficiency as well as the maximum torque capabilities.

\section{Results and Discussion}

8.1. Torque Capability. A set of computations were performed for machines with different slot/pole/phase, so that the maximum torque available could be calculated. The torque calculations obtained from the analysis are summarized in Table 8 . A common stator with 36 slots was used while the number of poles was varied to account for the machines between 2/7 SPP to 1/2 SPP. Analysis was carried out for the common stator of 24 slots as well. The relative width of the magnets was also kept constant in all cases at 0.86 . For the comparison, the following parameters were kept constant: rated power, speed and current density $10 \mathrm{~A} / \mathrm{m}^{2}$. Calculating torque analytically is based on the back EMF waveform

$$
T_{\mathrm{em}}=\frac{1}{\omega_{r}}\left[e_{a} i_{a}+e_{b} i_{b}+e_{c} i_{c}\right]
$$

where $e_{a}, e_{b}$, and $e_{c}$ are back EMF waveforms while $i_{a}, i_{b}$, and $i_{c}$ are phase current waveforms. $\omega_{r}$ is rotor mechanical speed.

8.1.1. Back EMF Waveform. The back-emf waveform can be calculated as shown by Zhu et al. in [12] by first calculating the flux density distribution in the air gap produced by the magnets, including the effect of the stator slots,

$$
\begin{aligned}
B_{\mathrm{oc}}(\theta, r) & =\tilde{\lambda}(\alpha, r) B_{\text {magnet }}(\theta, r) \\
& =\tilde{\lambda}(\alpha, r) \sum_{h} B_{h} \cos (h p \theta), \\
\theta & =\alpha-\alpha_{\mathrm{ma}},
\end{aligned}
$$

where $\theta$ is angular position with respect to the axis of the magnet, $\alpha$ is angular position measured from the axis of 
TABLE 6: Specifications of SPP $=2 / 7$ machine

\begin{tabular}{lc}
\hline Slot opening width & $2.5(\mathrm{~mm})$ \\
Slot top width & $11.4(\mathrm{~mm})$ \\
Slot height & $18.9(\mathrm{~mm})$ \\
Tooth width & $11.4(\mathrm{~mm})$ \\
Slot bottom width & $7.6(\mathrm{~mm})$ \\
Slot opening height & $3.0(\mathrm{~mm})$ \\
Back iron depth & $9.0(\mathrm{~mm})$ \\
Phase resistance & $0.32(\Omega)$ \\
Magnet depth & $3.2(\mathrm{~mm})$ \\
\hline
\end{tabular}

TABLE 7: Specifications of SPP=1/2 machine.

\begin{tabular}{lc}
\hline Slot opening width & $2.5(\mathrm{~mm})$ \\
Slot top width & $15.8(\mathrm{~mm})$ \\
Slot height & $18.9(\mathrm{~mm})$ \\
Tooth width & $13.5(\mathrm{~mm})$ \\
Slot bottom width & $9.6(\mathrm{~mm})$ \\
Slot opening height & $3.0(\mathrm{~mm})$ \\
Back iron depth & $9.0(\mathrm{~mm})$ \\
Phase resistance & $0.52(\Omega)$ \\
Magnet depth & $2.9(\mathrm{~mm})$ \\
\hline
\end{tabular}

TABLE 8: Maximum torque of SPM with various SPP.

\begin{tabular}{lcc}
\hline Slots/Poles & Winding factor & Max. torque $(\mathrm{pu})$ \\
\hline $24 / 28$ & 0.933 & $1.26 @ 2200 \mathrm{RPM}$ \\
$24 / 20$ & 0.933 & 1.64 @ 2700 RPM \\
$24 / 16$ & 0.866 & $2.01 @ 3400 \mathrm{RPM}$ \\
$36 / 42$ & 0.933 & $1.16 @ 2500 \mathrm{RPM}$ \\
$36 / 30$ & 0.933 & $1.42 @ 2900 \mathrm{RPM}$ \\
$36 / 24$ & 0.866 & $1.81 @ 3400 \mathrm{RPM}$ \\
\hline
\end{tabular}

phase A, $\alpha_{\text {ma }}$ is angle between the axis of phase A and the permanent magnet axis, $B_{\text {magnet }}$ is air gap magnet field, and $\tilde{\lambda}(\alpha, r)$ is permanence function, accounting for the slots of the machine.

The back EMF $e$ induced in each turn of a coil is simply then calculated by taking the derivative of the flux linkage which leads to

$$
\begin{aligned}
e & =-\frac{d \psi}{d t} \\
& =\tilde{\lambda}_{0} \sum_{h} 2 B_{h} R_{s} l_{\mathrm{eff}} \sin \left(h p \frac{\alpha_{y}}{2}\right) \omega_{r} \sin \left(h p \alpha_{\mathrm{ma}}\right) .
\end{aligned}
$$

8.1.2. Permeance Function. Relative permanence function accounts for the slotting effects (distribution of the magnetic flux in both the air gap and the magnets) in electrical machines. Reduction of the total flux per pole is accounted for by introducing the Carter coefficient $K_{\mathrm{c}}$. Both effects are incorporated into the field calculations using conformal transformations as shown by Zhu et al. in [12].

$$
\tilde{\lambda}(\alpha, r)=\sum_{\mu=0}^{\infty} \tilde{\lambda}_{\mu}(r) \cos \mu \mathrm{S}\left(\alpha+\alpha_{s a}\right),
$$

where $\alpha_{s a}$ is determined by winding pitch, and $\tilde{\lambda}_{0}$ is average value of permanence given by

$$
\tilde{\lambda}_{0}(r)=\frac{1}{K_{\mathrm{c}}}\left(1-1.6 \beta \frac{b_{o}}{\tau_{s}}\right) .
$$

It is clear from Table 8 that the $1 / 2$ SPP machine provides the best performance in terms of maximum torque capability of about $1.8 \mathrm{pu}$, while the $2 / 7 \mathrm{SPP}$ configuration is only capable of achieving about $60 \%$ of that performance. In addition, because of the lower pole count, the corner speed of the 1/2 SPP machine will be higher, resulting in the higher peak power. From this analysis, one can conclude that although a concentrated wound machine has a higher winding factor, it will not necessarily result in the highest peak torque/power. While it may be possible to optimize a slot/pole combination for a given application, simply changing a number of poles, while keeping the stator unchanged, to achieve a higher winding factor, will not always result in the higher performance machine. This can be due to several factors; higher pole count machines generally have higher relative magnet leakage flux; saliency ratio will change and in turn changing the optimal control angle which will affect the current distribution, that is, current waveform; some slot/pole combinations may be undesirable due to uneven magnetic pull, resulting in the torque decrease and other secondary effects. We will now look at the two particular machines (1/2 SPP) and (2/7 SPP) designed with the parameters Tables 6 and 7, respectively. Figure 13 shows calculated maximum power versus speed comparison for $\mathrm{SPP}=1 / 2$ and SPP $=2 / 7$ machines. Although the 2/7 SPP machine has an advantage in terms of extended speed range, the 1/2 SPP machine has better performance in terms of maximum power, which is more significant here, considering that for the given application the machine will be operated at a fixed speed. We now turn our focus on comparing the efficiencies of those machines.

8.2. Losses and Efficiency. The losses and the efficiency are calculated as described in Section 5. Table 9 presents a summary of the results. Although the efficiency of the half slot per pole per phase machine is slightly higher, the difference is so insignificant if compared to the accuracy of the methods used in calculating the losses of the machines. However looking, at the maximum torque capability, it is clear that the SPP $=1 / 2$ provides higher performance, and it would therefore be more suitable candidate for integrated starter/alternator application, considering that high starting torque would be required from the chosen machine.

8.3. Size and Weight Comparison. Considering the machine design for integrated starter generator in automotive application, one of the major considerations besides performance 


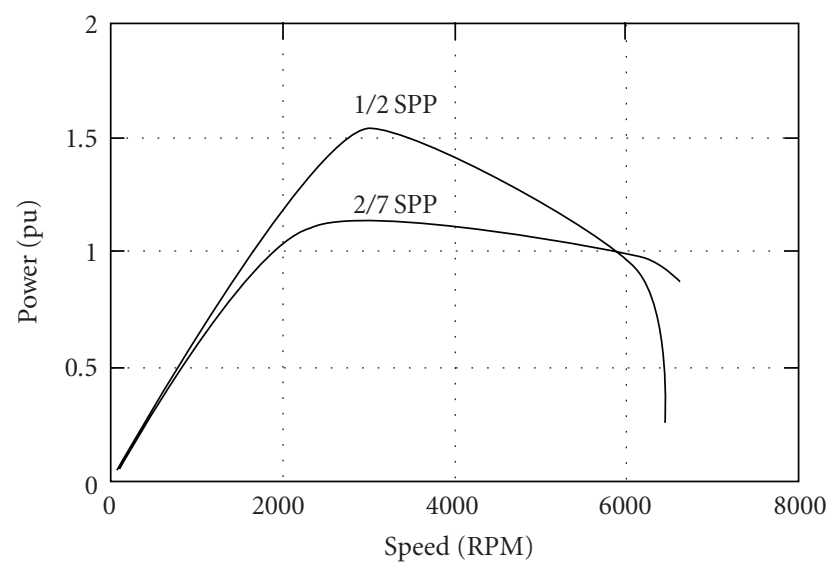

FIGURE 13: Power versus speed for the two machines.

TABLE 9: Summary of losses for the two machines.

\begin{tabular}{lcc}
\hline Parameter & Analytical & Simulated \\
\hline & SPP $=1 / 2$ & \\
Speed (RPM) & 6000 & 6000 \\
Power factor & 0.97 & 0.97 \\
$T_{\max }(\mathrm{pu})$ & 2.2 & 2.0 \\
$P_{\mathrm{fe}}$ & 168 & 211 \\
$P_{\mathrm{cu}}$ & 131 & 156 \\
$P_{\text {mag }}$ & 95 & 130 \\
$P_{\text {tot }}$ & 394 & 471 \\
Efficiency $(\%)$ & 93 & 92 \\
\hline & $\mathrm{SPP}=2 / 7$ & \\
Speed $(\mathrm{RPM})$ & 6000 & 6000 \\
Power factor & 0.97 & 0.97 \\
$T_{\text {max }}($ pu $)$ & 1.4 & 1.3 \\
$P_{\text {fe }}(\mathrm{W})$ & 182 & 230 \\
$P_{\text {cu }}(\mathrm{W})$ & 107 & 139 \\
$P_{\text {mag }}[\mathrm{W}]$ & 132 & 142 \\
$P_{\text {tot }}(\mathrm{W})$ & 391 & 511 \\
Efficiency $(\%)$ & 94 & 91 \\
\hline
\end{tabular}

is the size of the machine. Table 10 summarizes the size and weight comparison of the two machine candidates. It can be seen from the table that the SPP $=2 / 7$ design requires somewhat less magnet material, which indicates more costeffective design. However, the 1/2 SPP machine will have an advantage in terms of overall weight and length, which are reduced by $7 \%$ and $10 \%$, respectively, compared to $\mathrm{SPP}=$ 2/7 design.

8.4. Note on Demagnetization and Thermal Capability. Under normal operation, both machines, 1/2SPP and 2/7SPP, exhibit very little saliency, which means that for the optimal operation near or around peak power, a small $d$ axis current is required (between 0 and $15 \%$ of rated current for $1 / 2 \mathrm{SPP}$ and between 0 and $10 \%$ for $2 / 7 \mathrm{SPP}$ ); hence, demagnetization is not an issue at any operating temperature. The case of 3-phase short circuit and temperature
TABLE 10: Summary of size comparison.

\begin{tabular}{lcc}
\hline & $\mathrm{SPP}=2 / 7$ & $\mathrm{SPP}=1 / 2$ \\
\hline Active length $(\mathrm{mm})$ & 162.9 & 151.8 \\
Copper Mass $(\mathrm{kg})$ & 2.64 & 2.22 \\
Magnet Mass $(\mathrm{kg})$ & 1.44 & 1.51 \\
Iron Mass $(\mathrm{kg})$ & 6.81 & 6.16 \\
Total Mass $(\mathrm{kg})$ & 10.9 & 9.89 \\
\hline
\end{tabular}

of $120^{\circ} \mathrm{C}$ and above analysis of both machines shows some demagnetization at the lower corners of the magnets, that is, corners near the air gap however; this type of a fault is extremely rare, and protection design is beyond the scope of this paper.

It is important to point out that no thermal comparison is considered in this study. It is assumed that both machines will utilize the same cooling strategy (end winding oil cooling), and by keeping the current density, the same and similar volume in both machines, we can conclude that the thermal effects will be similar in both cases. In other words, adequate cooling of all the machines considered is assumed.

\section{Conclusions}

The paper presented a comparative study of permanent magnet machines for integrated starter-alternator application in series HE vehicle. Two machines in particular were closely examined: SPM machine with SPP $=1 / 2$ and SPM machine with $\mathrm{SPP}=2 / 7$. The machines are compared with respect to iron losses, copper losses, and losses induced in the magnets and maximum torque as well as the size and weight comparison. The analytical approach to estimating the losses is presented, which is useful as a starting point in the machine design. The analytical results are further verified through finite element simulation using Flux2D software. The torque capabilities of the two machine candidates are also assessed and compared. Although the efficiencies of both machine are relatively high, the difference between the two is minimal with the slight advantage going to $1 / 2$ SPP machine. However, after examining the torque characteristics, it is clear that this machine would be a better candidate for the starteralternator application since it is capable of maximum torque almost twice as high as that of 2/7 SPP machine. Machines size and weight were also considered with results favoring $1 / 2$ slot/pole/phase machine with $7 \%$ overall weight reduction.

\section{References}

[1] J. M. Miller, Propulsion Systems for Hybrid Vehicles, Institution of Electrical Engineers, London, UK, 2004.

[2] W. Cai, "Comparison and review of electric machines for integrated starter alternator applications," in Proceedings of the IEEE Industry Applications Conference, vol. 1 of IAS Annual Meeting no. 39, pp. 386-393, Seattle, Wash, USA, October 2004.

[3] L. Chedot, G. Friedrich, J.-M. Biedinger, and P. Macret, "Integrated starter generator: the need for an optimal design and control approach. Application to a permanent magnet 
machine," IEEE Transactions on Industry Applications, vol. 43, no. 2, pp. 551-559, 2007.

[4] A. M. El-Refaie, High speed operation of permanent magnet machines, Ph.D. dissertation, University of Winsconsin Madison, 2005.

[5] "24V Starters for Cumins Diesel Engines," 2007, http://www .acdelco.com.

[6] M. Ehsani, Y. Gao, S. E. Gay, and A. Emadi, Modern Electric, Hybrid Electric, and Fuel Cell Vehicles, CRC Press, Boca Raton, Fla, USA, 2004.

[7] A. S. Nagorny, N. V. Dravid, R. H. Jansen, and B. H. Kenny, "Design aspects of a high speed permanent magnet synchronous motor / generator for flywheel applications," in Proceedings of the IEEE International Conference on Electric Machines and Drives, pp. 635-641, May 2005.

[8] J. Cross and P. Viarouge, "Synthesis of high performance PM motors with concentrated windings," IEEE Transactions on Energy Conversion, vol. 17, pp. 248-253, 2002.

[9] F. Caricchi, F. Crescimbini, T. A. Lipo, and E. Santini, "Innovative inverter topology for concentrated winding PM motor drives," in Proceedings of the IEEE Power Electronics Specialists Conference, vol. 2, pp. 964-972, June 1992.

[10] K. Atallah, D. Howe, P. H. Mellor, and D. A. Stone, "Rotor loss in permanent-magnet brushless AC machines," IEEE Transactions on Industry Applications, vol. 36, pp. 1612-1618, 2000.

[11] D. Ishak, Z. Q. Zhu, and D. Howe, "Analytical prediction of rotor eddy current losses in permanent magnet brushless machines with all teeth and alternate teeth windingspart I: polar co-ordinate model," in Proceedings of the 71th International Conference on Electrical Machines and Systems (ICEMS '04), CD-Rom, 2004.

[12] Z. Q. Zhu, D. Howe, E. Bolte, and B. Ackermann, "Instantaneous magnetic field distribution in brushless permanent magnet dc motors-part I: open-circuit field," IEEE Transactions on Magnetics, vol. 29, pp. 124-135, 1993. 

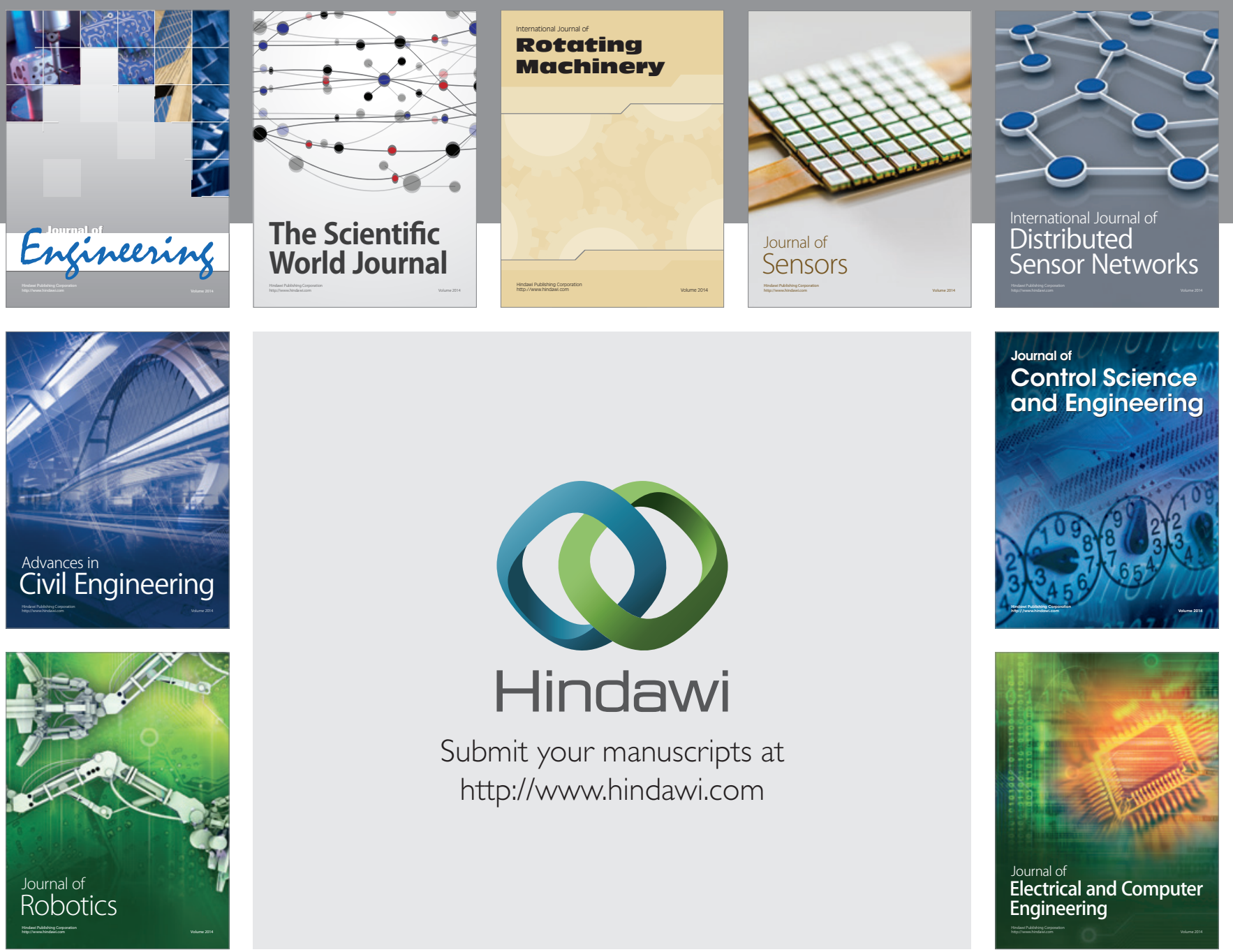

Submit your manuscripts at

http://www.hindawi.com
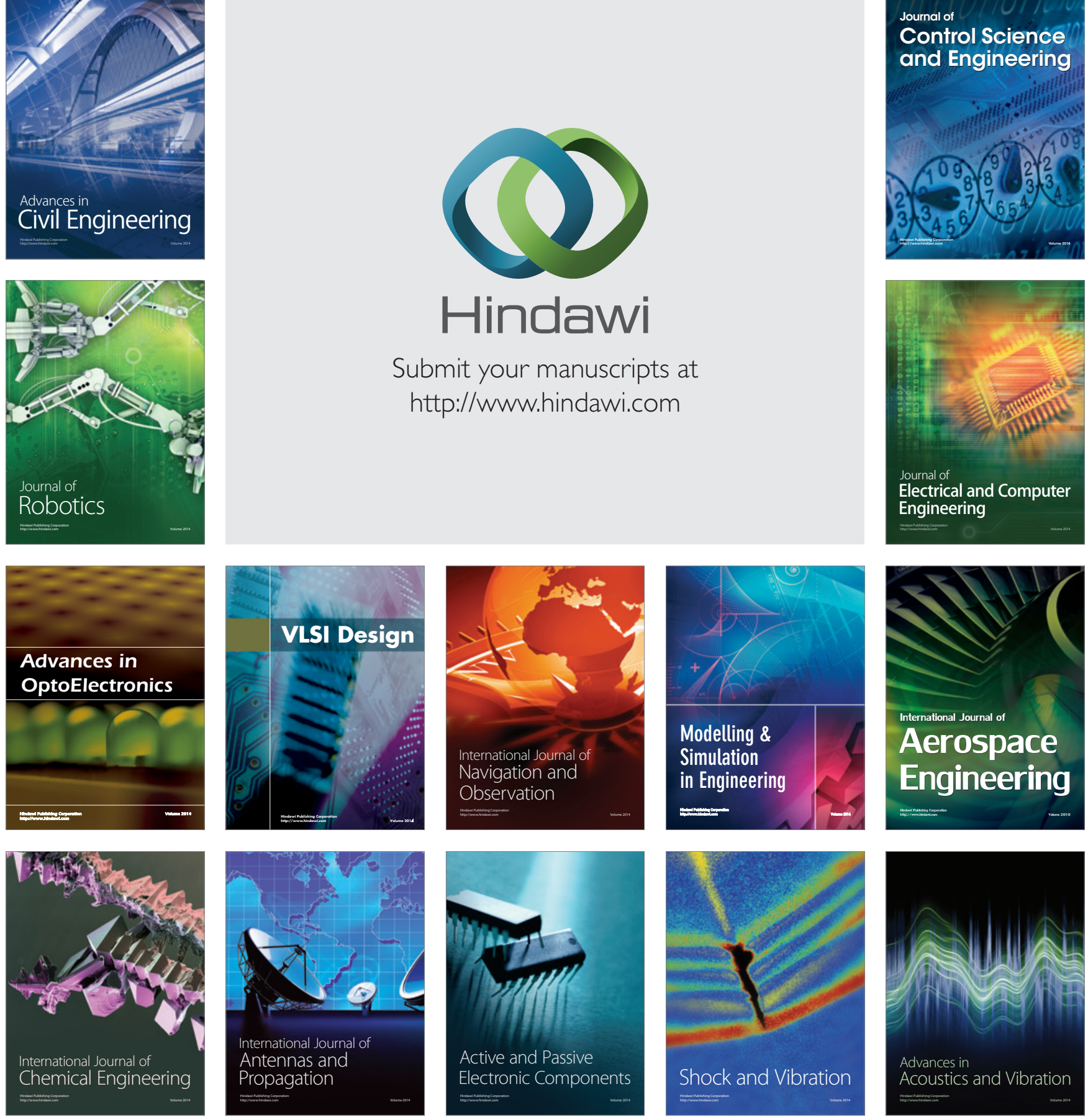